\title{
Application of BIM technology for surveying heritage buildings
}

\author{
Anna Galieva ${ }^{1, *}$, Denis Galiev ${ }^{1}$, Vladimir Alekhin ${ }^{1}$, Maria Chirkova ${ }^{1}$, and Laurence \\ Boswell $^{2}$ \\ ${ }^{1}$ Institute of Civil Engineering and Architecture, Ural Federal University, 19, Mira st., Ekaterinburg, \\ 620002, Russia \\ ${ }^{2}$ School of Engineering and Mathematical Sciences, City University, Northampton Square, London \\ EC1V 0HB, UK
}

\begin{abstract}
The preservation of heritage buildings is beyond doubt an important problem of today. The examination of a heritage building involves a number of problems, viz. missing design documentation, the need to find extant reports about technical condition of the building structures and building reconstruction projects prepared by different organizations, and nonconformance of data contained in drawings and documents of different organizations. In this paper the abovementioned problems are reviewed exemplified by the case of the federal heritagelisted building "Ekaterinburg State Academic Opera and Ballet Theatre", Yekaterinburg. The paper proposes the use of solutions based on information modeling methods for the examination of structures of the abovementioned building and reviews the possibility of employing these methods for upkeeping the building. The article demonstrates the practical value of the proposed application of a BIM model method comprising the building reconstruction stages for the structure survey on a specific example. The method proposed in the paper has a great practical value and can be employed for the improvement of normative and technical documentation, heritage building survey works, and for creating design documentation for restoration of buildings.
\end{abstract}

\section{Introduction}

Heritage-listed objects greatly influence the historical and cultural national identity and are of immense importance for maintaining and developing the personality of a nation and its contribution to the word culture. One of the most important tasks of a nation is the preservation of its heritage. Complex engineering and technical surveys are carried-out for the preservation of heritage buildings. Such surveys include the examination of condition of bearing and enclosure structures.Specialists responsible for carrying out the abovementioned survey works meet a number of difficulties viz. missing design documents, the need to find reports about surveys and reconstruction projects prepared by different organizations in the past, nonconformance of data given in drawings and documents of

*Corresponding author: a.b.galieva@gmail.com 
different organizations, poor condition of available extant documents, etc. This article proposes a concept for carrying out heritage building survey works using information modeling methods. Information support is necessary for the preservation of cultural and architectural heritage buildings.

Different aspects of the preservation of heritage buildings with the help of information technologies have been reviewed in many works of foreign [1-6] and Russian [79]scientists. The necessity of using information modeling methods for condition monitoring, preservation, restoration, and virtual remodeling of historical appearance of heritage buildings is noted widely. This article addresses the matters of applicability of the information model of the federal heritage-listed building "Ekaterinburg State Academic Opera and Ballet Theatre", Ekaterinburg.

The State Academic Opera and Ballet Theatre, founded in 1912, is one of the signature heritage buildings of Ekaterinburg. The building is located in the central district of Ekaterinburg. An examination of available extant design documentation and literature sources [10-12] showed that after many alterations and reconstructions undergone by the building only the northern part of the building volume (spectator area) remains intact. Specialists recommend considering this part in particular as a heritage preservation object.

\section{Proposed procedure}

The examination of normative documents and design documents for the object of survey available in archives allowed outlining the following difficulties and particularities involved in surveying heritage buildings:

1) At the preliminary stage there are difficulties in collecting and analyzing information because hard copies of drawings are retained in archives of different organizations, a unified full set of documents for the building does not exist, and old drawings do not reflect the actual situation. Quite often even owners, operating companies, and administrative authorities do not have a full set of documents for the building for whatever reason. Companies engaged in design and survey works have to seek out the required information in archives of different design organizations.

2) As regards visual examination there may be errors in records (defect and damage lists and diagrams) describing the nature and location of defects, i.e. descriptions and pictures of defect areas may not reflect the actual situation due to human error.

3) Measurement errors may occur during the detailed examination and lead to errors in design diagrams.

The proposed heritage building survey procedure allows reducing the risk of errors during the survey. The procedure consists of four stages:

1. Creating a BIM model incorporating all available information. In case the BIM model already exists it is necessary to examine its input data.

The BIM model of the building is adapted to different graphic editors and contains all information about materials, structures, communications, construction stages, reconstructions, interior finishing and facilities, and additional information like historical records (via data attributes for separate elements, web links, text or graphic files). The BIM model is easy to store, transfer, and modify. A single detailed study of all available information about the survey object when creating the BIM model is enough to avoid problems during preparatory and preliminary stages of surveys and reconstructions in the future.

2. Checking the correctness of the model using a cloud of points collected by laser scanning. In case the BIM model already exists it is necessary to analyze changes in the strain condition of building structures. 
Since some data from drawings on which the BIM model is based may be incorrect or even missing, and the BIM model can't reflect the actual condition of structures (strain and bending) at the moment of survey, the model shall be checked for conformance with reality. A traditional approach to performing measurement works has a number of downsides, viz. field works and data handling are time-consuming, weather conditions affect the performance of works, some measurement points can be hard to reach, human error factor, etc.

It is possible to increase the confidence level of the model by comparing it with the cloud of points or creating objects basing on the cloud of points attained by laser scanning. The laser scanning technology allows using a three-dimensional structure with maximum accuracy and efficiency, also the use of the laser scanning method allows for better safety of measurement works, especially for work at heights.

3. Performing structural calculations for a structure or a part of it basing on the refined 3D model using a numerical analysis software package. The results of the calculation shall be inputed in the BIM model.

Structural calculation allowing for deformation or calculation made basing on an updated diagram allow increasing the accuracy of results and, consequently, predicting the behavior of structures in preset conditions.

4. Drawing-up a building survey report basing on the results of the visual examination, instrumental examination, and calculations, using a premade electronic form.

5. Submitting the up-to-date information model to all concerned parties.

Therefore, the use of the procedure described above allows not only combining all available disconnected information about the object of survey, but simplifying the whole survey process by ensuring consistency and reliability of data.

\section{Example of application of the proposed procedure for surveying the Opera Theatre auditorium}

The building structure survey procedure proposed in this work was applied for surveying the auditorium part of the theatre since that particular part was classified as heritage-listed. All stages of the procedure were carried out in sequence.

At the first stage, a 3D information model of the building structure was created in the Revit software package. The model included all reconstruction results (alterations and additions) from the date of building to the present day (see the fig. 1).

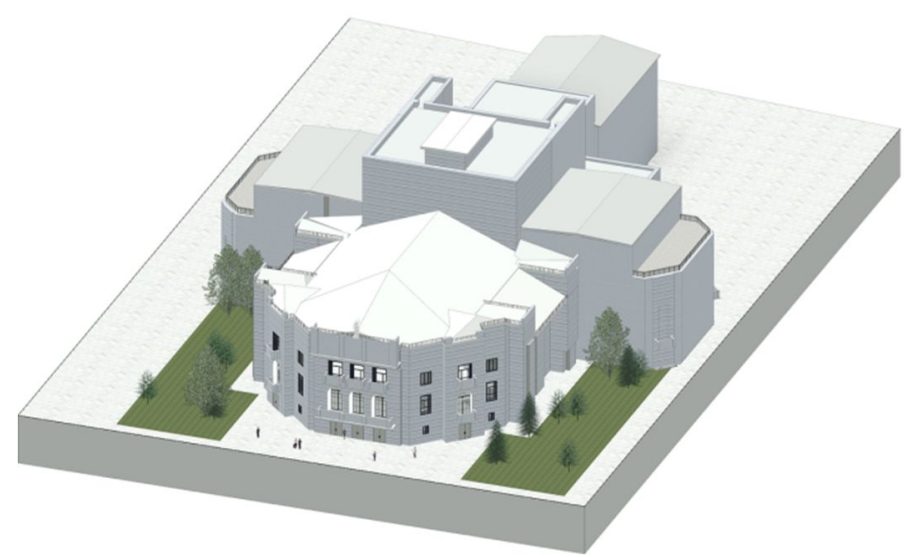

Fig. 1.Information model of the Opera Theatre building (design solutions) 
Several stages of the building life can be highlighted (fig. 2): the year it was built (1912, a), reconstructions in $60 \mathrm{~s}-80 \mathrm{~s}(\mathrm{~b})$, and the present days (c).

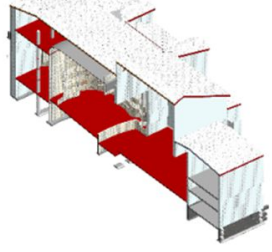

a)

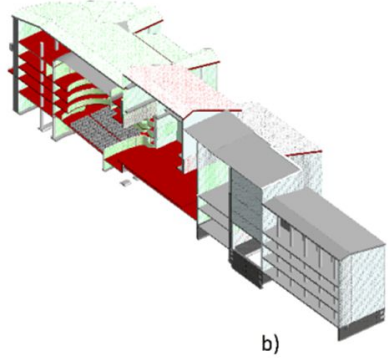

b)

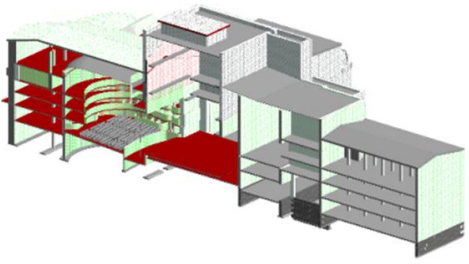

c)

Fig. 2. Stagewisemodeling of the Opera Theatre building: a) 1912, b) 60 s -80 s of XX century, c) present days

The model was also supplemented with additional information: pictures of old (dated from the time of Russian Empire) design concept drawings.

Information about the auditorium part was found to be very scarce and even available archive drawings contradicted each other. There was no information regarding the geometry of the auditorium ceiling. It was decided to employ laser scanning (fig.3) and compare the model created on the basis of drawings with the cloud of points using 3DReshaper software. The basics of surface laser scanning, fields of application, and data handling tools are described in details in the works [13-21].

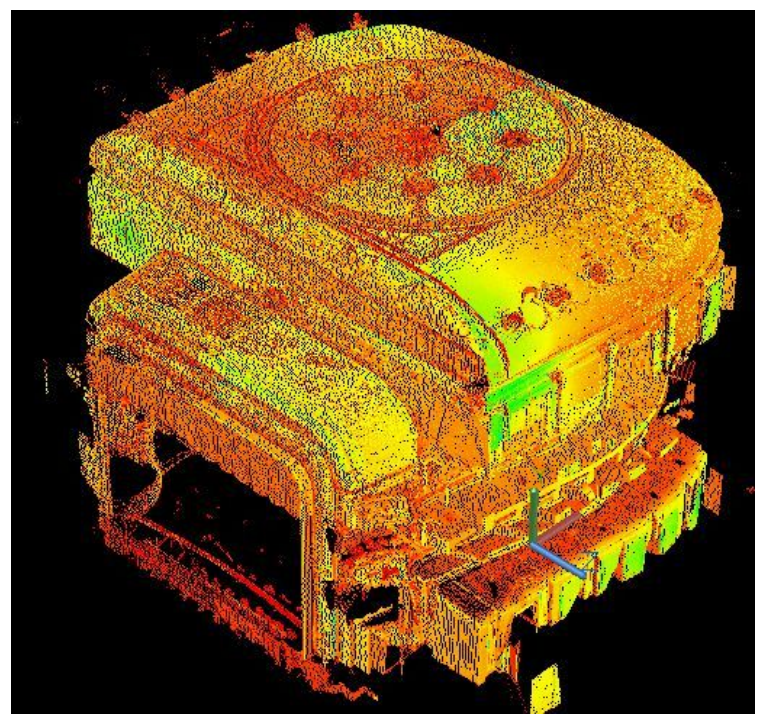

Fig.3. Results of laser scanning of the theatre auditorium (fragment)

Date processing showed that nearly $70 \%$ of the surveyed structures coincide with the model within 10 centimeters. The results of the comparison between the information model and the cloud of points are given in the fig.4. 

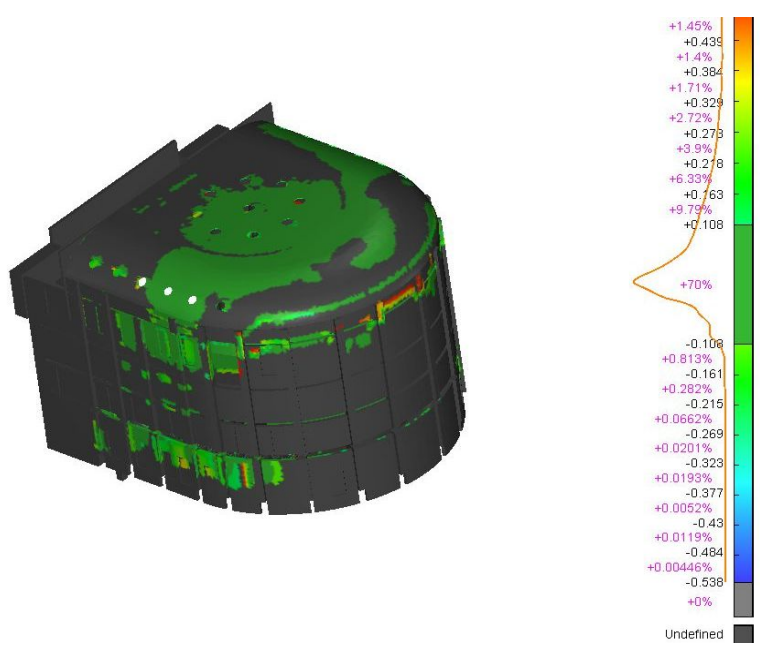

Fig.4. Comparison of the cloud of points and the information model

In addition, the study showed deformations of the auditorium ceiling. The basics of structure deformation monitoring methods in conjunction with 3D modeling technologies are described in the works [22-24].The results of the laser scanning were used for building the geometry of the auditorium and its ceiling.

The visual examination of the auditorium revealed many cracks and a high instability area on the ceiling. The cracks were non-through cracks $0.1-1 \mathrm{~mm}$ wide. Some cracks were located near holes for the ventilation system equipment. The proposed survey method allowed determining tentative causes of the defects. For example, the information model contains data about reconstruction and extension of the scene framework and configuration of the ventilation system above the auditorium ceiling. This information made it possible to suggest that the cracks in the high instability area were possibly caused by accidental dynamic loads and by the storage of materials during ventilation system installation works. The cracks near the ventilation holes were caused by making these holes, and the cracks in the between the auditorium structures and the scene framework were caused by the difference of settlements of these structures.

Service loading analyses of the ceiling structures was performed in LIRA SAPR and ING + software packages on the basis of the model created using Revit software. The analyses showed that the cracks and deformations observed on the ceiling could not be caused by the service loads. The results of the calculations carried out in two software packages were quite similar and show, that the bearing capacity of the ceiling, even considering the reduced strength in instability areas, is sufficient for supporting the own weight of the structure.

The model and the calculation results can further be used for monitoring the condition of structures.

\section{Conclusion}

The heritage buildings preservation topic is without doubt relevant and popular in the academic community. The use of information technologies is one of the research areas in the field of the preservation and survey of architectural, cultural, and historical heritage buildings. The use of the information technologies greatly contributes into the reorganization of the storage and usage of information about different heritage objects, facilitates and enhances the access to such information, and facilitates the development of different research, social, and educational projects. 
The method proposed in the article has a great practical value and can be employed for the improvement of normative and technical documentation, heritage building survey works, and for creating design documentation for restoration of buildings.

\section{References}

1. R.Brumana, D.Oreni, A.Raimondi, A.Georgopoulos, A.Bregianni, Digital Heritage, $497-504$ (2013)

2. S.Fai, K.Graham, T.Duckworth, N.Wood, R.Attar, CIPA(Conference Proceedings: XXIIIrd International CIPA Symposium, 2011)

3. S.Garagnani, A. M.Manfredini (4th ISPRS International Workshop "3D-ARCH”, 2013)

4. Yu. A. Vedenin, Information collection (1999)

5. M. Murphy, C. Dore, VSMM, 369-376 (2012)

6. S.Logothetis, A.Delinasiou, E.Stylianidis, CIPA(XXV International CIPA Symposium, 177-183, 2015)

7. A.V. Bykov, S.V. Pyankov, S.I. Kornienko, A.S. Kruglova, Collection of scientific works "Geoinformation support of spatial development of the Perm Territory",7, 103 110 (2014)

8. T.I. Kozlova, Bulletin of Tomsk State University. History,3, 33-37 (2013)

9. D.I. Zherebyatiev, Bulletin of the Peoples' Friendship University of Russia. Series "History of Russia",6, 68-74 (2010)

10. V.G.Veselovskaya, Academic Bulletin UralNIIproekt RAASN, 2, 59-61. (2011)

11. V.G. Desyatov, Konstantin TrofimovichBabykin: biographical sketch about the life of the master of architecture (2007)

12. O.A. Bessonova, N.I. Bugaeva, A.A. Voitenko, Collection of monuments of history and culture of Sverdlovsk region (2007)

13. T.A.Gura, A.E.Katerin, Young Scientist, 26, 25-28 (2016)

14. S. Parrinello, S.V. Maksimova, L.V. Sosnovsky, A.A. Shamarina, K.O. Mezenin, Modern methods of architectural survey of urban environment, 123 (2015)

15. V.A. Seredovich, A.V. Commissars, Terrestrial laser scanning, 261 (2009)

16. S. Bertocci,S.Parrinello, 15th International conference «LO-2012», 78 (2012)

17. S. Parrinello, S. Bertocci,R.Vital, Masada notebooks report of the research project, $\mathbf{1}$, 76-115 (2013)

18. D. N. Roy, Geoprofi, 2, 20-23 (2007)

19. N. Zimmermann,JbACErg.-Bd. ,35 (2002)

20. N. Zimmermann, G.Eßer, 2007, Proceedings of CAA “Layers of Perception”"(2007)

21. D.V. Komissarov, A.V. Ivanov, GEO-Siberia, 1,205-206 (2005)

22. A.V. Komissarov, D.V. Komissarov, T.A. Shirokova, V.A. Seredovich, A.V. Seredovich, G.N. Tkacheva, S.S. Studenkov, Geodesy and Cartography, 6, 12-14 (2006)

23. K.S. Loktionov, Geoprofi, 2, 25 - 27 (2010).

24. OS. Stepanova, Mining Information and Analytical Bulletin (Scientific and Technical Journal), 4, 418 - 422 (2014) 